\title{
Dimensión espacial y política de la reestructuración capitalista
}

\author{
DARÍO I. ReSTREPO*
}

\begin{abstract}
Most of public and academic opinions assume that the State decentralization processes and the citizen and community participation practices in public policies are highly positive. For many people, these are the contents of democracy, freedom and emancipation. The decentralization approaches decisions to the local government and participation to individuals. The appropriation of political power by the populace would be at hand after the fall of the socialist hope and the neoliberal attack. However, decentralization and participation are only understood in the context of capitalist restructuring process. In this sense, the special modalities of administrative and political organization of the common capitalist society are the basis upon which neoliberal strategy and socialist contemporary alternative are structured.
\end{abstract}

Keywords: capitalist restructuring process, decentralization, participation, alternatives to neoliberalism.

\section{Resumen}

La mayor parte de la opinión pública y de los académicos presume que los procesos de descentralización de los Estados y las prácticas de participación ciudadana y comunitaria en las políticas públicas son altamente positivas. Para muchos, son los nuevos contenidos de la democracia, la libertad y la emancipación. La descentralización acerca las decisiones a los gobiernos locales, y la participación a los individuos. La apropiación del poder político por la multitud estaría al alcance de la mano después del derrumbe de la esperanza socialista y la arremetida neoliberal. Sin embargo, descentralización y participación sólo pueden ser entendidas en el contexto de la reestructuración capitalista. En sentido estricto, son las formas espaciales de organización administrativa y política de la sociedad capitalista actual, con base en las cuales se estructuran la estrategia neoliberal y la alternativa socialista contemporánea.

Palabras clave: reestructuración capitalista, descentralización, participación, alternativas al neoliberalismo.

\footnotetext{
* Universidad Nacional de Colombia. Correo-e: direstre@colomsat.net.co
} 


\section{Especificidad del presente documento ${ }^{1}$}

Nuestra pretensión es el análisis de dos políticas públicas específicas: el proceso de descentralización y las prácticas de participación ciudadana y comunitaria. Ambas constituyen transformaciones importantes del Estado y la política en las sociedades capitalistas. Tienen la especificidad de aparecer como el lado amable de la reestructuración en curso, más aún, para muchos analistas, la descentralización del Estado y las prácticas de participación son los nuevos contenidos de la emancipación social, política y hoy también cultural, que se estarían enfrentando a la profunda hegemonía neoliberal.

Para muchos analistas y sectores democráticos, las formas de organización descentralizada de los Estados (transferencia ampliada de recursos financieros de la nación a las entidades territoriales, fortalecimiento político de los niveles subnacionales de gobierno, administración local de servicios) son consideradas, per se, más democráticas y eficientes que las formas centralizadas (Restrepo, 1991). ${ }^{2}$

Desde esta perspectiva, el gobierno local es asimilado al poder popular o, cuando menos, se le considera la instancia de gobierno más permeable y accesible a las necesidades de los sectores populares. El gobierno, las instituciones y el espacio nacional son leídos como el bastión de los intereses rentistas en el mundo de los negocios que se hacen en la política y el mercado. Las instituciones, los escenarios internacionales y el espacio global serían los bastiones de los poderes privados transnacionales y de los intereses imperialistas.

De tal manera, cierta mitología política contemporánea otorga a cada espacio una primacía de hegemonía social. A lo local correspondería lo popular, a lo nacional la burguesía rentista, a lo global el capitalismo transnacional.

Sobre esta base se analizan los procesos de descentralización. Se interpretan como el desprendimiento local (léase popular) del control antidemocrático de los poderes centrales (léase burgueses). Se propone así radicalizar la descentralización hacia la autonomía regional, la cual es asimilada como la autogestión social, máxima expresión del poder popular desatado de toda

\footnotetext{
${ }^{1}$ Este trabajo fue realizado para la Fundación Friedrich Ebert de Colombia - FEsCOL.

${ }^{2}$ En Restrepo (1991) desarrollamos una crítica a los supuestos epistemológicos y a la concepción política sobre la democracia en la asimilación entre descentralización y democracia.
} 
subordinación al capital nacional y trasnacional o se piensa que al menos la facilitaría. Las regiones autónomas -es decir, el poder popular local- serían los lugares por excelencia para la resistencia a la racionalidad trasnacional del capital, el que se expresa en el terreno global, es decir, en aquel que desconoce los valores, costumbres, instituciones y poderes políticos locales -por ende, comunitarios y populares. ${ }^{3}$

La asimilación entre lugares espaciales y primacías políticas sociales en curso -potenciales o deseables- es el resultado parcial de la reestructuración capitalista. Es cierto que la victoria arrolladora de la lógica capitalista se expresa en los procesos de globalización y trasnacionalización comercial, productiva, tecnológica y financiera, es decir, mediante la negación y subordinación de los espacios nacionales y locales. ${ }^{4}$ Es también cierto que los procesos de globalización debilitan los espacios, acuerdos y nichos de control nacional de mercados de las burguesías nacionales. Es finalmente cierto que la combinación entre globalización y crisis de los Estados Nación desmonta las conquistas sociales nacionales de los trabajadores y empuja la resistencia popular hacia las estructuras y funciones descentralizadas.

Pero lo anterior dista de asimilar un ámbito espacial del poder con una racionalidad social o más aún, identificar a lo local, las autonomías regionales y la autogestión social como la expresión más avanzada de los intereses y del futuro popular, suponerlos así implica un desconocimiento del contexto histórico en el que se generan los procesos de descentralización, así como de las estrategias neoliberales y clientelistas sobre esta materia.

Algo similar ocurre en el caso de las prácticas participativas. La apertura de las instituciones a la participación de los ciudadanos en los campos políticos de salud, educación, seguridad ciudadana, medio ambiente, las políticas de género, para la tercera edad, la niñez o las etnias conllevarían todas la democratización de la administración pública. Las prácticas políticas participativas son asimiladas al surgimiento de una democracia renovada y superior a la representativa, la democracia participativa.

\footnotetext{
${ }^{3}$ Para el análisis de la lectura de la correspondencia entre espacio y hegemonía social se sugieren textos como el de Fals (2000).

${ }^{4}$ En este escenario, se recortan las posibilidades de promover políticas autónomas de desarrollo local, las cuales están subordinadas a las decisiones de los capitales transnacionales (De Mattos, 1989).
} 
Las prácticas representativas o la democracia representativa ha llegado a considerarse como sinónimo de lo antipopular. Los partidos políticos y las elecciones no pueden garantizar el respeto de la voluntad popular porque se han colonizado por maquinarias electorales, el poder del dinero, el sistema clientelista de contraprestaciones y la manipulación de los medios de comunicación. Las instancias de la democracia representativa, (concejos municipales, asambleas departamentales y congreso de la República) son instancias carcomidas por la corrupción y las componendas, ante ellas, los intereses sociales y populares no prosperan. La democracia representativa aparece entonces como lejana, inasequible y autoritaria para los ciudadanos comunes y corrientes.

En cambio, se presume que las prácticas participativas ponen al alcance de los ciudadanos y las comunidades las políticas de interés colectivo. Por medio de la democracia participativa las comunidades podrían desprenderse del control de la burocracia, los partidos políticos elitistas y las relaciones clientelistas. El ritual electoral, como máxima incidencia de los ciudadanos en la política, sería superado por los procesos participativos que posibilitarían la cogestión, el seguimiento y el control de los programas públicos de manera permanente. Por lo anterior, la democracia participativa ayudaría a quebrar el monopolio del Estado burgués sobre la definición de las políticas públicas, permitiendo una incidencia directa de los beneficiarios sociales en ellas.

En resumen, el análisis es el siguiente: por medio de las prácticas representativas se expropió la política a los sectores populares y a la democracia. En cambio, se supone que las prácticas participativas permitirían la reapropiación de la política por los sectores populares en ejercicios trasparentes y democráticos.

Sin duda, estas ideas tienen su fundamento en la corrupción de la democracia representativa, la crisis de los partidos y de la política, así como en la apertura de espacios, instituciones y temas a la participación ciudadana y comunitaria.

Pero concluir, a partir de ello, que las prácticas participativas se inscriben en el sendero unívoco de la democratización de la administración pública y la redención popular, es una grave equivocación. Una vez más, es necesario considerar el contexto histórico que explica su popularidad y las diferentes estrategias políticas que usan los discursos y las prácticas participativas para fines, que como veremos, no son todos compatibles con los intereses populares y la democracia. 


\section{Reestructuración capitalista y fragmentación estatal}

Descentralización y participación son formas de organización de la política en el capitalismo contemporáneo, aquel que resulta de la crisis del Estado Nación y del Estado del bienestar. ${ }^{5}$

La globalización de la economía impulsa redes de integración de circuitos comerciales, productivos, tecnológicos y sobre todo financieros que trascienden las fronteras nacionales, lo cual podría caracterizarse como una tendencia a la desnacionalización de los espacios de acumulación. La materialidad y la espacialidad de los Estados Nación son un obstáculo al proceso de trasnacionalización del capital. El Estado Nación aparece como frontera de regulación, de instituciones que enmallan la circulación del capital, de sistemas tributarios, políticos, administrativos y monetarios que dificultan la libre circulación del capital. Es por eso que la globalización es también un proceso de desestatización del ahorro y de la propiedad social, requiere el desmonte de las fronteras arancelarias y monetarias, la desregulación de las actividades productivas y financieras, en fin, el debilitamiento del Estado y el fortalecimiento de los actores privados. ${ }^{6}$

Los procesos de globalización de los circuitos económicos, comerciales y financieros no comprometen por igual todas las actividades y territorios de un país. Por el contrario, sólo algunos sitios y actividades se conectan a los flujos trasnacionales, otros quedan subordinados mediante actividades secundarias y los más, relegados y al margen de la globalización. Aumentan así las disparidades internacionales y en el interior de cada país en cuanto a las tasas de crecimiento y los índices de calidad de vida entre regiones y ciudades. La propulsión de la diferenciación en los patrones de producción y consumo someten a los países a una muy fuerte tensión hacia la dislocación de la unidad politica, social y económica de las naciones.

Ya no es posible identificar las actividades y sectores capitalistas dominantes con un sector productivo específico o anclado a un territorio determinado. La transectorialización y transterritorialidad de los procesos de acumulación caracterizan los

${ }^{5}$ Cuatro grandes acontecimientos históricos explican la popularidad en el ámbito mundial de la descentralización y las prácticas participativas: el derrumbe de los países socialistas, la crisis del Estado del bienestar, el agotamiento del Estado-Nación y la crisis de la modernidad (Restrepo, 1994).

${ }^{6}$ En Restrepo (1992) se expone una propuesta teórica de interpretación de las incidencias de la reestructuración capitalista en los procesos de globalización productiva y descentralización estatal, con las consecuencias sobre los pactos políticos y sociales nacionales. 
agrupamientos y actividades fundamentales de los principales grupos capitalistas dominantes. Portafolios múltiples de inversión, movilidad del capital como en un juego de monopolio, entrada y salida expedita de un territorio y de un país, son las características de las actividades y grupos económicos dominantes en el ámbito mundial.

Si algo está globalizado en nuestro tiempo, es el capital financiero. Éste subordina en cada nación los procesos económicos, es decir, recoge el ahorro producido en las relaciones productivas y lo somete a la especulación financiera (Restrepo, et al., 1996). ${ }^{7}$ En el ámbito trasnacional, el capital financiero ha logrado desatarse de la racionalidad local y nacional y de las actividades productivas, aquellas que los economistas llaman el sector real. La mayor cantidad de intercambios en el mundo es de carácter financiero, por cada bien o servicio 'material' que se transfiere de un lugar a otro, ocurren sesenta y nueve transacciones financieras. Es por ello que el capitalismo contemporáneo tiende a la desmaterialización de la producción de la riqueza, crece vertiginosamente a través de productos virtuales, espumosos y volátiles. Las prácticas que completan esta característica son la destrucción del empleo en la generación de la riqueza y el énfasis en la información y la comunicación para la decisión de las inversiones, la propulsión de la velocidad en la rotación del capital y los bienes de mayor rentabilidad.

Es por ello que las bolsas de valores son el termómetro que mide la salud del capitalismo en el ámbito nacional y global. También se explica la gigantesca presión hacia la consolidación de Bancos centrales autónomos -de los capitalistas y clases políticas nacionales, se entiende- y que hacen de la monada el valor universal por excelencia. En el mundo contemporáneo la existencia de tantas monedas como naciones es un anacronismo. Mañana tendremos, inevitablemente, pocas monedas en el mundo, posiblemente tres o cuatro, una americana, otra europea, otra asiática y, quizás, una africana.

Mientras que el capitalismo rompe las fronteras nacionales, estatales, sectoriales, territoriales, materiales y de la fábrica y la oficina, la fuerza laboral lucha en el encierro de la fábrica, la aldea, el municipio, el sector productivo, tecnológico o administrativo determinado.

\footnotetext{
${ }^{7}$ En el trabajo citado, Jorge Iván González demuestra cómo el proceso de globalización conduce a la pérdida de la autonomía nacional en el manejo de la política fiscal y su subordinación a la política monetaria (González, 1996).
} 
Si el Estado Nación fue el contenedor de la fase de acumulación capitalista precedente, hoy es un obstáculo relativo que requiere ser debilitado y reestructurado. Las instituciones nacionales de los Estados son debilitadas en cuanto a las competencias en los procesos de integración económica y globalización. Con ello, los congresos de la república y los partidos políticos nacionales pierden funcionalidad y competencia, y se enfrentan a un proceso de crisis y degradación.

Los libros de texto de economía pregonaron como el objetivo de una buena política económica la integración y ampliación del mercado nacional. Más aún, las teorías de desarrollo económico -incluyendo en ellas a Keynes- tenían al espacio y el Estado nacional como horizonte. Hoy ya nadie habla de ello. Lo que importa es el control de variables macroeconómicas y la inserción competitiva en el mercado mundial, por lo que las políticas económicas, las instituciones y la normatividad construida hacia adentro para integrar el mercado nacional pierden vigencia, o desaparecen estrepitosa y precipitadamente. Abandonado el propósito de integración económica, institucional, social y política de las naciones, pierden sentido las teorías e instrumentos de la planeación del desarrollo en cada país y, por lo tanto, declinan las instituciones y programas motivados por este fin.

Debilitadas las funciones y las instituciones de carácter nacional, así como las políticas de integración nacional de mercados, se desatan buena parte de las condiciones que mantenían unidos los Estados bajo la forma centralista. El Estado-Nación es la materialización de poderes sociales, políticos y territoriales en sus instituciones, políticas, regulaciones y presupuestos. Por lo tanto, la crisis del Estado Nación sacude y socava el contenido social de todas las transacciones económicas, políticas y territoriales construidas durante el siglo Xx. Este es el contexto en el que ocurre la crisis de los Estados Nación y sus instituciones; en él se abren los procesos de negociación de competencias y recursos entre niveles de gobierno, los procesos de descentralización, los reconocimientos de comunidades autónomas, la regionalización de los Estados unitarios, la crisis de los pactos federativos o la explosión de los Estados.

La crisis del Estado Nación desata los pactos nacionales precedentes e inaugura una recomposición general de los modelos de desarrollo, el declive y fortalecimiento de actividades y sectores económicos dominantes, la decrepitud de ciertas formas de organización social y política, y el surgimiento de otras. En 
todos los casos se transforman las dimensiones espaciales del Estado, la economía, la política y la organización social.

La globalización propulsa nuevas formas espaciales de organización del poder y la descentralización es una de ellas. Expansión trasnacionalizada del capital y empequeñecimiento de los poderes administrativos estatales van de la mano. ${ }^{8}$ El capitalismo difuso o desorganizado, son dos maneras como se ha llamado a la nueva fase de acumulación del capital, en la cual, la extensión y dominio de las relaciones mercantiles ocurre mediante la fragmentación administrativa de los poderes estatales. El capitalismo fragmenta y atomiza las administraciones e instituciones estatales, las formas de organización gremial del trabajo y de los partidos políticos, para unificar por la vía del mercado los procesos de acumulación.

\section{Reestructuración capitalista y atomización de las agremiaciones socio-políticas}

Las formas de regulación básica del capitalismo en el siglo xx fueron el Estado del bienestar, y en la mayoría de países de América Latina -incluido Colombia-, el Estado patrimonialista del bienestar. ${ }^{9}$

Son varios los cambios introducidos en el desmonte de las funciones del Estado que conducen a la vigencia de la sociedad sobre el Estado y a las prácticas participativas sobre las representativas.

Desde la década de los años setenta, la crisis fiscal de los Estados y los procesos de inflación que resultaron del financiamiento de dichos déficit, fueron presentados como explicación de los bajos índices de crecimiento económico y las bajas en la productividad y competitividad de las empresas. El financiamiento de las funciones del Estado no se compadecía con la producción general de riqueza en la sociedad, lo cual disparó el uso y abuso de la emisión monetaria, la carga impositiva y el recurso a la deuda pública. Los neoliberales afirman que de esas tres maneras se penalizó al sector privado, al cual se le expropió una gran tajada del ahorro que concentró el Estado para mantener la pesada carga de sus funciones.

${ }^{8}$ Una lectura muy sugestiva sobre la relación entre globalización, crisis de los Estados Nación y procesos de descentralización, formulada a partir de la experiencia de los países del capitalismo avanzado de Europa occidental se encuentra en Bauman (1999).

${ }^{9}$ Un análisis de las consecuencias que sobre la política social acarrea la crisis del Estado patrimonialista del bienestar se encuentra en Novoa y Restrepo (1996). 
A partir de este diagnóstico comenzó en la década de los años ochenta una presión ascendente hacia la reducción del Estado empresario en asuntos comerciales, productivos, financieros, de infraestructura, de comunicaciones y de servicios. Es lo que se conoce como el inicio de las privatizaciones. La 'devolución' de las empresas y funciones al sector privado se presentó desde el comienzo como el retorno a una primacía de lo social sobre lo estatal; como la liberación de las energías emprendedoras de los individuos y las empresas, de trabas, monopolios y el peso parasitario de políticos y burócratas agazapados en el poder estatal.

De la misma manera, las conquistas laborales en términos de salarios, seguridad social, salud, pensiones y toda una serie de subsidios fueron presentadas como privilegios injustificados ante la pobreza y marginalidad en la que estaba sumida la mayoría de los trabajadores no asalariados. ${ }^{10}$ La participación de los trabajadores en los ingresos fue denunciada como contraria a la necesidad de concentrar el ahorro en los sectores empresariales con el fin de que estos últimos elevaran la inversión y la generación de empleo. El ataque a las conquistas laborales, a la participación de los salarios en la riqueza y a los subsidios, alimentó un discurso sobre una mayor participación de los beneficiarios de las políticas sociales en su financiamiento.

En el desarrollo de esta veta, se diseñaron políticas a favor de la población rural, informal y pobre que solicitó la participación activa de los beneficiarios en los costos de las políticas, ya fuera mediante su contribución en trabajo no remunerado, o mediante la organización (cogestión) de las obras y proyectos de desarrollo social.

Desde la década de los años ochenta -y en Colombia de manera más clara en los noventa- se empezaron a quebrantar los principios rectores de la seguridad social. Los precarios esquemas de solidaridad, construidos a través de transferencias de recursos entre clases sociales para financiar las políticas sociales y la seguridad social, así como el principio de la solidaridad de las generaciones de trabajadores con las venideras empezaron a ser cuestionados. A cambio, se promovió 'la libre elección indivi-

\footnotetext{
${ }^{10}$ En Colombia, bajo el gobierno de Misael Pastrana (1970-1974) y López Michelsen (1974-1978), inició la crítica a los 'privilegios' de los asalariados y la necesidad de formular políticas sociales hacia la población pobre, con una especificidad que seguiría discutiéndose en lo sucesivo, como es el caso de la consideración de la población prioritaria de las políticas sociales, independientemente de su vinculación a relaciones laborales formales y estables. Lo cual, desde sus inicios, se acompañó de una serie de ataques contra la organización sindical y las relaciones laborales estables.
} 
dual' de cada trabajador ante un abanico de sistemas de aseguramiento en salud y pensiones. La misma 'libertad' caracterizó la elección de los pobres subsidiados entre las empresas públicas y privadas que prestan servicios de salud y mediante las que pueden acceder al sistema de aseguramiento. ${ }^{11}$

Los servicios que condicionan las posibilidades de reproducción de la fuerza laboral interpelan al ciudadano en su capacidad de ahorro y a las redes familiares, étnicas, comunales y barriales para que participen de su autoreproducción y sostengan la solidaridad con los más desvalidos. Se trata de un retorno, como en otros asuntos, a principios y prácticas anteriores al Estado del bienestar. ${ }^{12}$ No es exagerado afirmar que en el capitalismo contemporáneo los sectores punta de la acumulación logran sus mayores tasas de crecimiento económico destruyendo puestos de trabajo y exigiendo a los Estados el desmonte del financiamiento de la reproducción del trabajo mediante los impuestos directos al capital, ${ }^{13}$ para a cambio recurrir a los impuestos llamados indirectos, al consumo y las tarifas, es decir, a los que gravan principalmente a las clases medias y bajas de la población.

En este contexto cobra un especial sentido el llamado a la participación de los usuarios en las políticas de su interés; así como la defensa que se hace desde altos cargos del Estado, la alta tecnocracia y las agencias internacionales, a la autogestión comunitaria, la autoayuda, la superación del paternalismo estatal y la participación responsable de la población pobre en las políticas públicas.

Es de gran interés señalar que el ámbito de organización de la nueva política social es el territorio, más precisamente, las localidades, los barrios y hasta las cuadras y manzanas. ${ }^{14}$ Las políticas de focalización de los grupos vulnerables (mujeres cabeza de hogar, niños pobres, población en zonas de riesgo natural, po-

${ }^{11}$ En Colombia, el supuesto principio de la libertad de elección anima las normas que regulan el régimen subsidiado en salud, a partir de la constitución política de 1991.

${ }^{12}$ El filósofo anarquista italiano, Antonio Negri, afirma que, de tal manera, se da por terminada la corta época reformista del capital, aquella en la cual el desarrollo del capitalismo (teorizado por Keynes), requería, como condición de su propia primacía, la extensión de la relación laboral y una mejoría en el bienestar de los trabajadores.

${ }^{13}$ Esta es una tesis fundamental de uno de los libros más populares de los últimos años en contra de la racionalidad de la reestructuración capitalista y sus consecuencias (Forester, 1996).

${ }^{14}$ Por ejemplo, las “obras con saldo pedagógico” impulsadas por la alcaldía de Enrique Peñaloza $(1998$ - 2000) en Bogotá, a través del Departamento de Acción Comunal, convocaron la participación comunitaria en obras que escasamente tuvieron impacto sobre los barrios, ya que la mayoría de los proyectos focalizaron su impacto en la cuadra de residencia de la población ganadora del concurso participativo. 
bres y en Colombia las víctimas de la violencia) condicionan su éxito a la capacidad de localizar exactamente el territorio en el que se encuentra el beneficiario para centrar la intervención de las instituciones estatales, comunitarias y privadas. Las políticas de focalización de la inversión pública, así como los subsidios a la demanda y la cultura de proyectos comunitarios comparten un mismo contexto: el renacer de la vida local y las prácticas participativas.

También comparten el abandono de toda pretensión de cobertura universal de las políticas que apoyan la reproducción del trabajo. La nueva política social ante los pobres se otorga a través de tres características de la política social del Estado: El Estado bombero y camillero, el Estado piñata y aleatorio, y el Estado cínico. Bombero y camillero, porque en vez de desplegar instituciones y programas de cobertura universal corre detrás de las catástrofes naturales, económicas y políticas, para ofrecer benévolamente programas de emergencia circunstanciales, de corta duración y de impactos insostenibles. Piñata y aleatorio, porque selecciona a los pobres y la población vulnerable a ser atendida entre una marea creciente de marginales y desechados por el sistema. Cínico, porque discrimina entre iguales, es decir, entre la población igualmente necesitada mediante concursos y elaboración de proyectos por los pobres para que éstos compitan entre sí, unos contra otros, por ganarse las migajas de las políticas de focalización. Cínico, reiteramos, porque mientras las políticas tributarias recaen sobre las clases populares y medias, a la vez que se protege y se desgravan las grandes fortunas, se exige de los pobres financiar las políticas de interés colectivo, todo a nombre de la solidaridad, la responsabilidad, la autogestión y la decisiva participación ciudadana y comunitaria.

\section{El nuevo paradigma del desarrollo y la democracia}

En términos generales, la crisis del Estado del bienestar implica un cambio de paradigma, es decir, un cambio en la concepción y práctica del desarrollo y la democracia. Desde el primer tercio del siglo pasado, todo asunto de interés colectivo de gran sensibilidad social tendió a convertirse en un asunto de Estado. Al problema del acceso a la tierra se respondió con la creación del Instituto Nacional de Reforma Agraria, a la necesidad de expandir la capacitación de la fuerza laboral le sucedió el sistema nacional de educación, a los requerimientos de una fuerza laboral medianamente sana, la nacionalización del sistema de salud. 
Es decir, el Estado Nación creó instituciones especializadas con burocracia propia, presupuestos crecientes, normatividad, regulación específica y responsabilidades en los territorios para cada necesidad del desarrollo social. No sobra señalar que, en el cumplimiento de todas las funciones tendentes al adiestramiento y reproducción de la fuerza de trabajo, dichas competencias fueron expropiadas a los gobiernos locales y centralizadas en el ámbito nacional. De esta manera, las demandas sociales se politizaron al ser conducidas hacia conquistas en el Estado central de presupuestos, programas y legislaciones favorables a los sectores populares.

Con la crisis del Estado del bienestar y el Estado Nación se ataca el núcleo de esta cultura política. Se trata de desmontar las condiciones estructurales que la alimentaron. En esta perspectiva, es necesario el proceso de privatización de empresas y funciones estatales. También se requiere acabar con 'los privilegios' de los asalariados, quebrantar la fortaleza de sus organizaciones y desmontar los regímenes laborales en las empresas de las cuales se nutren. No menos necesario es descentralizar sobre niveles inferiores de gobierno las políticas sociales, para las cuales se abre la inmensa mayoría de las ofertas estatales en participación ciudadana y comunitaria. Por último, como requisito y consecuencia de lo anterior, es necesario debilitar el poder político del Estado, la regulación y control sobre el sector privado, el ahorro estatal, el poder de la burocracia, la democracia representativa y los partidos políticos nacionales. Esta es una de las explicaciones a que, en el mundo contemporáneo de los últimos veinte años, se haya desarrollado una campaña ininterrumpida contra el Estado y la política por parte de los grupos económicos más poderosos. ${ }^{15}$

Para el nuevo paradigma que emerge con la reestructuración capitalista la responsabilidad social, privada, individual y comunitaria respecto de las necesidades de la población no es una dádiva, sino el núcleo de la nueva cultura política que se quiere inocular. Se hace un llamado a la libertad y la responsabilidad de cada cual ante sus necesidades y la solidaridad con los otros. El Estado concurre como socio benévolo con el sector pri-

${ }^{15}$ La política y la democracia, como se les conoce hasta ahora, basaron su ámbito territorial en la nación y el Estado. Los procesos de globalización generan actores más poderosos que la mayoría de los Estados existentes. Esto lleva a varios autores a hablar del fin de la política y la democracia, a cambio del reino de las transacciones privadas con apoyo de parcelas estatales dominadas por la tecnocracia (véase Guéhenno, 1995). 
vado y los beneficiarios de las políticas públicas en el financiamiento y coadministración de las obras de interés social. En términos generales, el proceso de reestructuración capitalista quiebra el compromiso histórico construido durante el siglo xx entre la sociedad de mercado, el Estado benefactor y la democracia representativa liberal. ${ }^{16}$

Debemos insistir sobre un asunto que no es mera casualidad. La 'nacionalización' de las políticas necesarias para la reproducción social durante el siglo Xx -básicamente de salud, educación, seguridad social y vivienda- requirió la construcción de un sistema tributario, instituciones, regulaciones y programas centrales. La burocracia, la democracia representativa y los agremiados del capital y el trabajo, transaron sus conflictos y programas alrededor de estas agencias centrales. Ahora, los procesos de descentralización y participación ciudadana facilitan el abandono de la responsabilidad estatal en la reproducción de la fuerza de trabajo; para hacerlo, se debilitan las burocracias centrales, se desvanece la unidad política de los partidos y se atomiza la fuerza de agremiación del trabajo en un sinnúmero de prácticas e instancias de participación.

\section{Globalización capitalista y globalización alternativa}

De lo anterior se concluye que la actual descentralización de las políticas sociales y sus mecanismos de participación ciudadana y comunitaria hacia los gobiernos locales, sólo pueden ser entendidos en el contexto de la reestructuración capitalista que resulta de la doble crisis del Estado Nación y del Estado benefactor.

Ahora bien, el contexto general esbozado es el telón de fondo en el cual se recomponen las estrategias de diferentes actores sociales, políticos y territoriales. ${ }^{17}$ Aquí consideraremos solamente dos estrategias tipo, ${ }^{18}$ la neoliberal y la del campo popular,

\footnotetext{
${ }^{16}$ Una clara y contundente sustentación de esta tesis y de las consecuencias generales de los procesos de globalización se encuentra en Beck (1998).

${ }^{17}$ En otro trabajo (Restrepo, 2000) presentamos las estrategias de los neoliberales, la clase política reformadora, el clientelismo, los nuevos movimientos sociales, las guerrillas, los paramilitares y el narcotráfico respecto del proceso de descentralización en Colombia.

${ }^{18}$ El concepto de estrategia tipo o tipológica no debe ser confundido con el accionar y el pensar de una organización política o social determinada. Es una abstracción del sentido estratégico general atribuido a un sector o clase social. Tiene por mérito 'reducir la complejidad' de las prácticas, luchas, posturas y plataformas que diferentes actores ponen en juego ante la transformación de un contexto general en mutación. De esta manera, permite ordenar un esquema de interpretación de los sentidos estratégicos en disputa y por lo tanto, facilita la elaboración de criterios para la acción política. Tiene,
} 
particularmente de los llamados nuevos movimientos sociales o más ampliamente, nuevas subjetividades políticas. ${ }^{19}$

No debe sorprender el encuentro de similitudes entre las tendencias generales de la reestructuración capitalista y la estrategia neoliberal. Después de todo, el neoliberalismo es un ensayo de racionalización de las necesidades de la reestructuración capitalista. Sin embargo, la doctrina y las propuestas neoliberales no describen exactamente lo que está sucediendo en la realidad, puesto que ésta escapa -afortunadamente- a la determinación de una sola racionalidad. En este sentido, las políticas neoliberales son un programa político, un deber ser, dentro de las tendencias de la reestructuración de la sociedad, el Estado y la política en el capitalismo contemporáneo. ${ }^{20}$

Antes de considerar las dos estrategias mencionadas es necesario revisar la fortaleza de otras globalizaciones en curso, todas ellas surgen de la reestructuración capitalista. Nos referimos a las oportunidades que dan las nuevas tecnologías de la comunicación a la lucha por la emancipación. Los últimos acontecimientos contra el Banco Mundial, el Fondo Monetario Internacional y la globalización capitalista, han sido posibles gracias a las redes de activistas esparcidos por el mundo entero, pero conectados en tiempo real por el correo electrónico. Innumerables campañas se emprenden a diario para la protección de los indígenas del Ecuador, el bosque en Bolivia, los derechos humanos en Colombia, la pesca de las ballenas en el mar pacífico, la denuncia de los efectos de los grandes proyectos petroleros que impacten en la supervivencia de las culturas locales, los derechos de los pueblos a su autodeterminación y la defensa de un mínimo de garantías para el ejercicio de la democracia.

Dicho en otras palabras, asistimos al mismo tiempo, a una lucha por los contenidos de la globalización y a la puesta en la escena mundial de las luchas locales. En el primer caso, se trata

sin embargo, una desventaja, ser una generalización racionalista y reductora de la realidad, la cual siempre es más compleja e imbricada que las tipologías de intervención estratégica Por lo tanto, no es suficiente para distinguir escenarios específicos para el accionar político.

${ }^{19}$ Advertimos al lector que hablar de estrategias de los neoliberales y de movimientos sociales ante la descentralización del Estado y las prácticas participativas, esconde la pluralidad de corrientes e innumerables prácticas que desde estos sectores se ponen en práctica. A pesar de esta advertencia, esperamos que se encuentre una utilidad en el ejercicio que sigue.

${ }^{20}$ Más aún, hablar del pensamiento neoliberal como pensamiento único es forzar la realidad. El neoliberalismo contiene varias corrientes que hacen énfasis específicos y no siempre compatibles. Incluso se advierte que varias reformas fundamentales del neoliberalismo entran en franca contradicción de propósitos y resultados, ejemplos de estas contradicciones las explicamos en Restrepo (1994). 
de la irrupción a escala global de valores que se desean de cobertura universal: los derechos humanos, el ambiente, la democracia, la autodeterminación de los pueblos, el pacifismo, y la no discriminación de las personas por creencias religiosas, ideas políticas, genero, prácticas sexuales o culturales. Los valores promovidos a escala global levantan límites a la lógica de la acumulación económica y a las prácticas de dominación política. En sentido estricto, se trata de valores postmaterialistas que disputan el sentido del nuevo orden global. Al principio de la competencia se le opone el de la cooperación, contra el reino de los intereses privados se defienden los intereses sociales, la libre circulación del capital trata de ser sometida a principios de regulación y defensa de los derechos de las comunidades locales y nacionales.

En el segundo caso, la defensa y promoción de las luchas locales rebasan el ámbito territorial en que se generan, para acudir a la escena global en búsqueda de apoyos. De este modo, se trasnacionalizan los actores de las luchas locales, más aún, las resistencias locales a la explotación y la dominación se juegan cada vez más claramente, por la capacidad de involucrar en la lucha local a actores de otras localidades y a las redes de actores trasnacionalizados. Para estos últimos, los valores postmaterialistas y la escena global son el propósito y el ámbito territorial de su constitución. Por ejemplo, Green Peace, Amnistía Internacional y las redes de activistas contra la globalización económica.

La globalización alternativa a la lógica del capital posee gran importancia para entender las estrategias neoliberales y populares ante los procesos de descentralización y las prácticas participativas. Mañana, con seguridad, el escenario global se volverá inconturnable en la lucha, reclamos y resistencias locales al proceso de trasnacionalización del capital. Falta, sin embargo, plantear una unidad global que supere las resistencias locales y construya el manifiesto de la nueva utopía, la cual será global, o no será. $^{21}$

\section{La estrategia neoliberal de descentralización}

El interés básico de los neoliberales en el proceso de descentralización es la inoculación de las reglas del mercado en el funcionamiento del Estado. Tanto el sistema de transferencias, como la

${ }^{21}$ El Primer Foro Social Global realizado en Brasil durante el mes de enero del 2001 es un paso trascendental en esta dirección. 
distribución de competencias entre niveles de gobiernos, e incluso el sistema político deberían ceñirse por los principios que rigen a las empresas privadas. Éstos son el autofinanciamiento, la competencia, la eficiencia financiera y administrativa, y la sanción final del desempeño empresarial por el consumidor. Para lograrlo se requiere transformar las administraciones locales en empresas territoriales, someterlas al principio de rentabilidad financiera en el cobro de los valores de los productos vendidos y ajustar el tamaño de la administración al desempeño económico local. ${ }^{22}$ Veamos algunas líneas de la acción política neoliberal en descentralización.

\subsection{El sistema de transferencias debe premiar a los más eficientes en el cobro de impuestos a los ciudadanos}

Desde 1986 se introdujo en Colombia la ley que consignó la cesión del impuesto al valor agregado, IVA, de la nación a las localidades, y se condicionó un porcentaje a la obtención de promedios en el cobro de impuestos locales. Las reformas introducidas en 1991 a la clave de repartición de recursos a las localidades, ampliaron los rubros y la incidencia de la condicionalidad del monto de las transferencias al esfuerzo tributario local, a la reducción de los costos administrativos con relación al gasto total y a la reducción de los índices de necesidades básicas insatisfechas.

El conjunto de fuentes de cofinanciación de proyectos entre la nación y los gobiernos locales, así como los programas de focalización de beneficiarios exigen contrapartidas a los gobiernos locales. De esta manera, los créditos nacionales y los recursos de los fondos se han concentrado en las entidades territoriales de mayor capacidad tributaria local.

Del mismo modo, el acceso a recursos del Ministerio de Hacienda y Crédito Público, para superar la profunda crisis fiscal de las entidades territoriales, está condicionado a una disminución de las plantas de personal, la reducción de salarios, al aumento de la carga tributaria local y al logro de mayores desempeños en coberturas de servicios con menores costos relativos.

\footnotetext{
${ }^{22}$ Una revisión de las propuestas de los tecnopolíticos neoliberales criollos sobre la descentralización durante los últimos veinte años se encuentra en Restrepo (2000b).
} 


\subsection{Las fuentes de financiamiento de las políticas locales deben estimular la competencia entre entidades territoriales por los recursos ofrecidos}

El principio de la competencia gobierna la totalidad de los recursos del crédito público, la cultura de proyectos que se extiende como patrón que condiciona: el financiamiento de las entidades públicas, los fondos de cofinanciación, el fondo nacional de regalías, los proyectos de focalización de la inversión pública, y los programas presidenciales y de diversos ministerios.

La competencia busca premiar a los que realicen mayor esfuerzo tributario propio y a los más eficientes desde el punto de vista de la ampliación de servicios a menores costos administrativos (esto es el equivalente a lo que en términos de mercado se llama reducción de los costos marginales por unidad de producto). Claro está que la inoculación del principio de la competencia de mercado en el sector público está acompañado de otra competencia, la de la apropiación política de los recursos entre diversos aparatos electorales y entre facciones políticas de diferentes niveles de gobierno. El resultado es, como en casi todos los aspectos de la descentralización, una combinación entre la lógica de mercado y la reproducción política clientelista. ${ }^{23}$ Por esto no debe sorprender ni es contradictorio hablar de un clientelismo neoliberal.

\subsection{La descentralización de competencias hacia los gobiernos locales facilita los procesos de privatización de las empresas}

La literatura tecnopolítica neoliberal explica, desde la década de los años ochenta, la necesidad de avanzar en un proceso de descentralización para abolir de tajo funciones estatales, suprimir entidades y privatizar otras.

El traspaso de funciones a los gobiernos locales debe estar acompañado de crecientes transferencias de recursos que, sin embargo, no deben ser suficientes para cubrir el costo real de su prestación. De manera que los gobiernos locales se ven abocados a subir las tarifas de los servicios, desmontar los subsidios a los estratos más bajos, reducir personal, incrementar los impuestos y

\footnotetext{
${ }^{23}$ Las principales leyes de la descentralización, así como las características básicas del proceso en Colombia pueden ser leídas a través de las contradicciones, negociaciones y transacciones entre la lógica del mercado y las relaciones clientelistas. El desarrollo de esta tesis se encuentra en Ochoa y Restrepo (1997).
} 
privatizar las empresas. Esto es lo que ha ocurrido en Colombia de manera ininterrumpida con las empresas municipales en la última década.

\subsection{El ajuste de las instituciones locales al tamaño de los mercados y a los desempeños económicos de los gobiernos}

¿Cuál es el tamaño óptimo del Estado? Los autores neoliberales y los sucesivos gobiernos han oscilado y vacilado ante la disminución del tamaño del Estado y del gasto público como condición irremplazable para alcanzar la eficiencia financiera.

Por ejemplo, para el Informe sobre las Finanzas Públicas Intergubernamentales (Bird, 1981), el tamaño del Estado es indiferente en la discusión sobre su eficiencia, lo importante son las funciones que debe tener y desprenderse de aquellas que no le corresponden; así como la organización de las instituciones y niveles de gobierno para el desarrollo de competencias bajo principios de mercado que deben guiar el gasto público.

En cambio, la Comisión del Gasto Público (Velázquez, 1986) estima que sin una reducción del tamaño del Estado y del gasto no es posible el logro de su eficiencia y por lo tanto, tampoco del sector privado que se ve penalizado por el Estado ineficiente.

El estudio doctrinario de Wiesner (1992) desprecia la reducción per se del tamaño del Estado y defiende la búsqueda de un óptimo que está dado por lo que los ciudadanos puedan y quieran pagar por la compra de servicios de calidad y a precios reales.

La Comisión de Racionalización del Gasto Público (Rosas, 1997) implora la urgencia de reducir drásticamente el tamaño del Estado para recortar el déficit público y lograr la tan anhelada eficiencia, mediante la privatización de funciones estatales y la socialización de los costos de las políticas públicas.

Los textos y reformas impulsadas por el Departamento Nacional de Planeación y del Ministerio de Hacienda y Crédito Público en el cuatrienio presidencial de Andrés Pastrana insisten nuevamente sobre la necesidad de reducir el tamaño del Estado y el gasto público, las trasferencias a las entidades territoriales y el costo administrativo de los gobiernos locales para lograr la pregonada y esquiva eficiencia de mercado.

Con o sin reducción del tamaño del Estado, se trata de construir instituciones locales que cuesten lo que los ciudadanos -a través de los impuestos y el pago de los servicios a precios 
reales- estén en capacidad de financiar. El desempeño financiero y administrativo de las administraciones locales debería determinar su tamaño, la cantidad e intensidad de las funciones asumidas y el grado de autonomía política alcanzable. Cabe señalar que las funciones estatales descentralizadas son las referidas a las políticas sociales y que los grandes consumidores de las políticas públicas sociales (salud, educación, transporte, vivienda) son las clases populares.

\subsection{Mientras las reglas del mercado unen el manejo de las empresas descentralizadas, la agremiación social y politica se fragmenta}

Desde el punto de vista político, la estrategia neoliberal busca descentralizar los conflictos y localizar las resistencias sociales. Se pretende debilitar la fortaleza de los trabajadores del sector público nacional mediante la autonomía local de las empresas, lo que conduciría a una inevitable fragmentación de las expresiones gremiales.

\subsection{Las politicas de reproducción deben ser la frontera de las luchas sociales locales}

El nuevo sujeto social prioritario de la administración es el individuo consumidor de los servicios, no las fuerzas sociales ni los sindicatos nacionales. El proceso de descentralización busca reducir los conflictos sociales a demandas por la extensión y calidad de servicios públicos y protegerse de las luchas por la propie$\mathrm{dad}$, los impuestos y las decisiones del mercado.

\subsection{La función de los gobiernos locales es la tecnificación de la politica}

Como el ciudadano escoge mediante el acto electoral a sus mandatarios, y los gobiernos locales deben llegar a ser exclusivos responsables de los servicios que prestan con participación ciudadana, los votantes y ciudadanos participativos deben llegar a ser los únicos responsables del resultado de las políticas y desempeños de los gobiernos locales. ${ }^{24}$

\footnotetext{
${ }^{24}$ Esta tesis se encuentra presentada con total claridad por el expresidente del Banco Central Hipotecario durante muchos años, véase Calderón (1987).
} 
Así, la contienda política local debe girar básicamente alrededor de las opciones que diferentes candidatos presentan en cuanto a las destrezas gerenciales en el manejo de alternativas, técnicas de satisfacción de demandas y prestación de servicios. ${ }^{25}$

\subsection{La competencia entre entidades territoriales para atraer las inversiones y la gestión local de la seguridad ciudadana}

Como referencia de la estrategia de descentralización se encuentra la construcción de las ciudades competitivas. Quien asegure una clase trabajadora disciplinada, unos sindicatos debilitados, buenos servicios e infraestructura a bajos costos administrativos y sistemas óptimos de seguridad y vigilancia triunfará en la convocatoria de las inversiones nacionales e internacionales, privadas y públicas. La pista y las reglas para la competencia entre entidades territoriales por las inversiones están abiertas. En muchos países se promocionan las ciudades en este sentido y en Brasil se habla ya de la guerra fiscal entre estados y ciudades por ofrecer exenciones tributarias para la inversión privada (Prado y Cavalcanti, 2000).

\subsection{La globalización de la riqueza y la localización de la pobreza}

El capital busca desatarse de los controles y regulaciones nacionales y estatales, con ello se ha acelerado de manera vertiginosa la acumulación y centralización del capital en pocas firmas, en pocas manos. Algunos centenares de personas -380 según las Naciones Unidas- concentran más recursos que el 60\% de las naciones del mundo; mientras tanto, crece la marginalidad y la pobreza.

El reclamo de la libre movilización del dinero, las mercancías y la tecnología es tan fuerte como las trabas a la libre circulación del trabajo. Los Estados Nación y en ellos los gobiernos locales, son llamados, los primeros, a extremar los controles a la emigración y los segundos, a gerenciar las políticas para la reproducción del trabajo y la asistencia a los pobres.

\footnotetext{
${ }^{25}$ Nadie ignora que, por ejemplo en la ciudad de Bogotá, las cualidades técnicas de los candidatos y la discusión sobre alternativas gerenciales para el manejo de la ciudad son los puntos centrales de las últimas contiendas electorales, así como el criterio principal de los medios de comunicación para calificar el desempeño de la administración local.
} 


\section{La descentralización desde el campo popular}

El sentido general de la forma descentralizada del Estado y la política es facilitar la apropiación popular del poder. Construir una administración de la riqueza y la prestación de servicios al alcance de los productores. El espacio local sería el mejor ámbito para instrumentar tecnologías con rostro humano, es decir, que no sometan y alienen al trabajador, y que sean respetuosas de la naturaleza. A la vez, el gobierno popular local permitiría la participación de los trabajadores en las decisiones sobre el desarrollo local y las políticas de distribución del excedente. La escala local del poder reivindica la biodiversidad y el pluralismo cultural, étnico y religioso. ${ }^{26}$ Veamos someramente algunas de las políticas que componen esta estrategia:

\subsection{La apropiación territorial de la democracia}

La construcción del Estado Nación se realizó mediante un proceso ininterrumpido de expropiación de los poderes regionales, de sus tributos, ejércitos, monedas, códigos del comercio, empresas y facultades de regulación económica. También supuso la 'nacionalización' de una serie de políticas, como las referentes a salud, educación, construcción de vivienda popular y desarrollo de infraestructura de comunicaciones. Por último, se hizo en desmedro de la pluralidad étnica y cultural constitutiva de la nacionalidad colombiana y de muchos países en todos los continentes.

El Estado-Nación se rigió por instituciones, un orden político presidencialista y centralizado, así como por modelos de desarrollo centralizados y concentrados.

La 'devolución' de competencias y recursos de la nación a las entidades territoriales pone al alcance de los conflictos locales el ejercicio del poder sobre las funciones descentralizadas. Es una oportunidad para construir la dimensión espacial de la democracia, más exactamente, su dimensión local. Sin embargo, cabe advertir aquí lo que ya debe estar claro: el poder local no es el poder popular, también puede ser el poder de los empresarios, los caciques políticos, la burocracia, las mafias o sectores militaristas de derecha o izquierda. Más aun, así el gobierno local fuera conquistado por los sectores populares, las principales decisio-

\footnotetext{
${ }^{26}$ El texto de Schumacher (1978) es el más esclarecedor entre los que conocemos y que trata sobre las virtudes de los espacios locales dentro de una estrategia de refundación de la economía y la política.
} 
nes de inversión de capital y alta tecnología no se toman en el ámbito local, ni en el nacional, sino con una lógica transnacional.

\subsection{La descentralización del modelo de desarrollo}

El Estado Nación se desarrolló bajo modelos de desarrollo centralizados y concentrados en cuanto a extensión territorial y difusión social de los beneficios del crecimiento económico. El proceso de descentralización, dentro de una perspectiva popular, brega por la descentralización del modelo de desarrollo, es decir, por la cobertura en todo el territorio nacional de los bienes y servicios necesarios para gozar de una calidad de vida digna.

El centralismo en el Estado-Nación creó en todas partes centros y periferias. Las ciudades dan cuenta de esta discriminación de la intervención del Estado en infraestructura y servicios por barrios y zonas. El proceso de descentralización en una perspectiva alternativa lucha por la difusión social de los beneficios de la intervención del Estado y del desarrollo.

\subsection{De la descentralización administrativa al desarrollo local y regional}

Durante las décadas de los años sesenta y setenta dos prioridades de la política económica fueron: la lucha contra las disparidades en el desarrollo regional y la generación de muchos polos de desarrollo. El proceso de descentralización administrativa y la crítica a la intervención del Estado en la economía sepultaron estas pretensiones. Se cree que el mercado es sabio en cuanto a las decisiones sobre los lugares de inversión. La igualación de los grados de desarrollo regional es no sólo imposible sino indeseable, pues desvía recursos hacia zonas y poblaciones menos productivas. Para el caso colombiano, esta tesis puede consultarse en Weisner (1995).

Desde una perspectiva alternativa, es necesario recuperar la discusión sobre el desarrollo local y regional, luchar contra las disparidades de la inversión pública entre el campo y la ciudad, y superar la frontera de la descentralización como mera desconcentración de las políticas sociales. Algunos de los temas que deben ser tratados por los gobiernos locales para incidir en el desarrollo son: la política agraria y urbana, el acceso a crédito y tecnología, la inversión productiva, los circuitos comerciales, y la explotación de los recursos del suelo y del subsuelo. 


\subsection{El control del excedente económico}

La estrategia neoliberal exige la plena libertad de movilidad del capital, la posibilidad de exportación de las ganancias y bajos tributos a las empresas. Las actividades capitalistas más avanzadas han desterritorializado sus compromisos y mueven inversiones como en un juego de monopolio. Deslocalizan los centros de decisión, el diseño de las estrategias de integración productiva y comercial y los flujos financieros. Afectan el empleo en cada una de sus decisiones, consumen la infraestructura y se niegan a asumir compromisos con el desarrollo local. Han logrado que ya no sea necesario satisfacer la demanda local antes de poder exportar los productos y tienen la posibilidad de ser los inversionistas mayoritarios de los recursos y empresas estratégicas para el desarrollo nacional y, con mayor veras, local.

De esta manera, el control estratégico sobre los fines del sistema productivo escapa cada vez más a toda intervención nacional en cualquier esfera estatal. Una política de descentralización alternativa debe buscar la negociación de partes del excedente económico de las actividades empresariales para invertir en el desarrollo local. Del mismo modo, controlar el impacto de las inversiones sobre el ambiente y exigir compromisos con el financiamiento de la infraestructura local.

\subsection{Dos concepciones de la autonomía}

Pocas esperanzas son abrasadas con mayor facilidad que la expectativa de autonomía política y autogestión de los asuntos locales, inducidas por un proceso radical de descentralización. Debemos advertir que pocas consignas poseen tanto peligro como esta.

En efecto, las versiones más radicales del neoliberalismo aspiran a la autonomía total de las localidades. Entienden por autonomía la plena aplicación del principio: 'sálvese quien pueda y tenga los medios para ello', que significa el desprendimiento total de la responsabilidad de la nación con las políticas de reproducción social que se descentralizan. Exigen el autofinanciamiento local en cuanto a gastos administrativos y costos de las políticas de interés y exclusivo beneficio de los habitantes del lugar.

Los cuantiosos tributos que recauda el Estado central, preferentemente por la retención en la fuente y los impuestos al consumo, no serían ya destinados al financiamiento de políticas 
públicas. Los consumidores locales de salud y educación pública, que son las clases medias y bajas de la población, deberían pagar una segunda vez los servicios del Estado a precio real, mediante las tarifas y una tercera vez, mediante crecientes impuestos locales.

Por último, la autonomía local para los neoliberales posibilitaría el imperio absoluto del reino de la competencia entre entidades territoriales para ganar los recursos del Estado central y atraer a los inversionistas privados.

La autonomía local y la autogestión social y política, desde una perspectiva diferente, refieren a la concentración del poder popular en el ámbito local y a grados mayores de negociación con los poderes nacionales e internacionales. La autonomía significa además, la libre determinación popular sobre las mayorías políticas que gobiernan, el respeto a las prioridades del desarrollo local y la plena vigencia de las especificidades culturales, regionales y étnicas.

\subsection{Contra el encerramiento local del trabajo, la apropiación del poder local en un mundo global}

Ya advertimos cómo para el neoliberalismo, la descentralización permite empujar las luchas sociales hacia los ámbitos locales, las cuales a su vez, quieren ser reducidas a exigencias de consumidores sobre bienes y servicios comprados y a la rendición de cuentas que los votantes pueden pedir a sus mandatarios.

Desde una perspectiva popular, la descentralización no conduce a un encerramiento, sino a la apropiación del poder local para negociar las condiciones de la vinculación a los procesos culturales, productivos, comerciales, tecnológicos y financieros globales. No defendemos ningún chauvinismo localista, sino la congregación, en estas negociaciones, de redes de apoyos de otras localidades, activistas y organizaciones trasnacionalizadas, con base en la defensa de valores comunes, es decir, globales.

\section{El sentido de las prácticas participativas desde estrategias neoliberales}

\subsection{Abaratar los costos de la reproducción del trabajo aumentando la legitimidad del Estado}

La participación ciudadana y comunitaria en las políticas públicas abarata los costos de la reproducción del trabajo de varias 
maneras. Mediante el trabajo social no remunerado, la contratación con organizaciones populares, gremios sociales y fundaciones sin fin de lucro que no generan relaciones contractuales estables con su corolario de derechos salariales y de seguridad social. Las comunidades aportan además información, organización social y administran parte de los programas que reciben, con lo cual colaboran para abaratar los costos administrativos de los proyectos. Además, la participación en la priorización y ejecución de proyectos aumenta la legitimidad de las acciones estatales.

\subsection{Forzar la competencia dentro de las comunidades por los recursos}

La oferta estatal en participación ciudadana y comunitaria inaugura una competencia entre individuos, comunidades y organizaciones sociales por los beneficios de los proyectos. De este modo, en vez de estimular la unidad de los sectores populares y organizaciones sociales o de aquellas que trabajan por el desarrollo social, se estimula una competencia de unos contra otros.

\subsection{Incentivar la conversión empresarial de las organizaciones sociales}

Para competir por los recursos del Estado, de la cooperación internacional o de las grandes fundaciones del sector empresarial, se exige a las comunidades y pobladores organizarse de manera empresarial para optar por la firma de contratos.

\subsection{Transformar los pliegos de peticiones y las demandas sociales al Estado en proyectos de desarrollo}

Así, las demandas y reivindicaciones sociales al Estado y al mercado reciben una gigantesca presión. Deben abandonar las prácticas beligerantes a cambio de la formulación de propuestas de desarrollo susceptibles de contratación.

\subsection{La mercantilización y contractualización de las relaciones entre el Estado y los sectores populares}

Los cuatro objetivos enunciados arriba buscan la contractualización de las relaciones sociales, despojar las relaciones entre capi- 
tal y trabajo, comunidades y administración pública, usuarios y empresas estatales y privadas de la pugnacidad que las ha caracterizado. A cambio, se pretende convertirlas en relaciones entre socios ligados en la obtención de fines consignados en contratos.

De igual manera, la frontera de las relaciones sociales entre el Estado y los sectores populares debe ser un horizonte mercantil, es decir, una transacción de bienes y servicios y de valores monetarios. Se pretende desvalorizar los contenidos políticos de las relaciones sociales y nublar las alternativas estratégicas de reconstrucción política y ética de la sociedad y el Estado.

\subsection{Quiebre de la externalidad entre el Estado y el mercado con los sectores populares}

En la fase capitalista precedente los trabajadores construyeron varios gremios, todos ellos caracterizados por mantener una externalidad respecto de las funciones estatales y privadas. Las organizaciones levantaron pliegos y demandas para arrancar al Estado y al mercado beneficios para sus agremiados y sectores sociales amplios.

Ahora, la estrategia neoliberal de participación busca superar dichas distancias, mediante el involucramiento activo de los sectores populares, las comunidades y las organizaciones sociales en el cofinanciamiento y coadministración de las políticas públicas. El objetivo es construir sujetos parapúblicos, es decir, corresponsables con el Estado y el capital privado en la administración de las políticas de interés colectivo en relación de dependencia; y sujetos paramercantiles, es decir, empresarios que manejen recursos públicos y compitan en el mercado. Clara lógica que pretende responsabilizar a los trabajadores de su miseria o superación y que busca generar las condiciones estructurales de la imposibilidad de la insubordinación radical a la lógica del capital y la dominación política.

\subsection{La superación de la lucha de clases y el reino de los ciudadanos consumidores, votantes y contribuyentes}

La oferta neoliberal de participación reconoce a los individuos usuarios de las políticas como sujetos susceptibles del derecho a la participación en las políticas de su interés. Las organizaciones gremiales de diverso tipo no son convocadas a la participación y difícilmente los son las organizaciones sociales o comunitarias. 
La estrategia busca eliminar las condiciones estructurales de agremiación de intereses sociales, para sólo reconocer ante sí a los individuos aislados en su condición de compradores, usuarios, contribuyentes y votantes.

\section{El sentido de las prácticas participativas desde los nuevos movimientos sociales}

\subsection{La satisfacción de las demandas sociales}

La aspiración fundamental de las prácticas participativas desde el campo popular es la satisfacción de las demandas sociales con el fin de mejorar la calidad de vida y ampliar el campo de las realizaciones; participar en la definición de las políticas de interés colectivo y en las instituciones y procesos donde éstas se deciden, para superar las necesidades biológicas y mover la frontera de las aspiraciones culturales. En este sentido, el objetivo de la participación es la cobertura universal de las políticas sociales y de beneficio colectivo, lo cual se enfrenta irremediablemente a la focalización selectiva, aleatoria y circunstancial de beneficiarios impuesta por el neoliberalismo.

El campo popular aspira a bienes y servicios de calidad y no a los remedos de solución que se emprenden con carácter paliativo y que el pretexto de la urgencia y la escasez de recursos otorga para ciudadanos de segunda y tercera categoría.

El sentido mínimo del ansia de participación desde el campo popular es universalizar el acceso a bienes y servicios de calidad, que superen las condiciones de precariedad y la sumisión de la inmensa mayoría de la población al 'rebusque' y afán por la satisfacción mediocre de las necesidades biológicas.

\subsection{La promoción de la democracia directa y la disolución de los intermediarios}

Ya sabemos, la pobreza es inseparablemente producto de la privación de condiciones materiales y la carencia de condiciones de poder político de representación, defensa y promoción de intereses populares.

No hay, por lo tanto, posibilidad alguna de mejoría sostenible y general de las condiciones de vida materiales sin fortalecimiento de las capacidades políticas. Es por ello que la política social neoliberal, además de ser paliativa, cultiva la dependencia 
de los ‘sujetos beneficiarios' de las políticas respecto de los burócratas y los caciques políticos. ${ }^{27}$

Para el campo popular, el referente de la participación en las políticas públicas es el aprendizaje del ejercicio de gobierno: fortalecer las organizaciones, conocer las instituciones y el marco de regulación, apropiarse de los derechos y ensanchar los beneficios sociales de las inversiones estatales, pero, sobre todo, apropiarse del poder institucional, lo cual supone la construcción de actores sociales y políticos populares.

Debe ser otro el poder institucional a construir, no basta con insertar algunos programas sociales en los presupuestos públicos, tampoco ensanchar las élites que manejan el Estado. Se trata de crear otra institucionalidad, una que se base en el mandato popular, en la que los mandatarios no se eleven por encima de la voluntad popular.

En la coyuntura colombiana, esta aspiración se materializa mediante la exigencia de la rendición pública de cuentas a los elegidos y a los directivos de los programas públicos frente a la población sobre las acciones estatales.

De la misma manera, no basta con la elección popular de alcaldes, este evento no contiene ningún valor intrínseco superior a la elección de presidente de la república o de los senadores en el congreso. La nueva institucionalidad política inscrita en los intersticios íntimos de las ansias de participación social no es la elección popular de alcaldes, sino la elección de alcaldes populares. Y ello sólo puede ser el resultado de otra manera de hacer política, aquella en que asambleas en corregimientos, veredas, barrios y sectores sociales establecen el programa de gobierno y otorgan un mandato a candidatos para los cargos públicos, que rendirán cuenta a la población sobre sus actos y realizaciones.

\subsection{La limitación del poder del Estado y de los agentes del mercado}

Las ofertas participativas neoliberales pretenden fortalecer la autoridad y legitimidad del Estado y adoctrinar a las comunidades en comportamientos empresariales dentro de la extensión de

${ }^{27}$ Un ejemplo dramático de las consecuencias de los programas sociales neoliberales son las políticas para desplazados por la violencia en Colombia. A las poblaciones que todo lo han perdido, que salvaron su último bien: la vida, renunciando a sus propiedades, a su terruño, a las redes familiares y a sus destrezas, se les exige presentar proyectos para que los burócratas de la Red de Solidaridad Social y los políticos benevolentes decidan aprobar lo que ellos, en su 'magnificencia', tengan a bien aceptar. 
las relaciones mercantiles. La participación popular, por el contrario, se inscribe dentro de una política de limitación al poder estatal como ente desprendido, suspendido por encima de una sociedad a la que somete. Las prácticas participativas populares tienden a controlar al Estado y a valorar las razones y necesidades sociales que la racionalidad del mercado niega.

Sin embargo, la limitación del poder del Estado y del mercado acarrea una dificultad como pocas, la historia no está de nuestro lado. El movimiento popular durante el siglo xx abatió una cantidad apreciable de Estados burgueses y restringió en igual medida el imperio del mercado, pero el precio fue la construcción de Estados totalitarios que desarrollaron la lógica imperial y autoritaria como sólo pudieron hacerlo de manera más efímera los Estados fascistas a mediados del siglo.

En el siglo XXI no podemos reeditar el esperpento del comunismo real. El reto de la participación popular es mantener a ralla el poder estatal capitalista y, a la vez, construir formas institucionales no totalitarias. Repetimos, dificultad como ninguna otra, porque se trata de no oponer una totalidad institucional a otra aun más autoritaria y corrupta.

Por eso las prácticas participativas actuales deben ser al tiempo construcción y vivencia del socialismo alternativo. Es decir, difusión del poder, respeto a la autorrealización, freno al poder estatal, comunitarización de las decisiones y disolución de los macropoderes. En la sociedad occidental no existen antecedentes de prácticas como estas, por lo que nos adentramos aquí en un terreno de innovación que reta a la imaginación y la tensa al máximo.

\subsection{La socialización de la política pública}

El referente de las ofertas participativas neoliberales es la privatización de la política. Cada cual debe promover sus intereses privados e individuales, unos contra otros, ganadores contra perdedores. Por esta razón es tan peligroso canalizar todo el esfuerzo de movilización social hacia el copamiento de las ofertas estatales en participación y subsumirse en las inestables agendas, precarias rutinas y cambiantes temas de la oferta estatal en participación. ${ }^{28}$

\footnotetext{
${ }^{28} \mathrm{El}$ contraste entre las ofertas estatales y las demandas sociales en participación lo trabajamos en Restrepo (1997).
} 
Por el contrario, la participación popular busca la socialización de la política de dos maneras. Por una parte, la socialización de los espacios de decisión, arrebatando el monopolio a los burócratas, tecnócratas, políticos profesionales y de manera creciente, a los gerentes del capital privado. Por otra, socializando los beneficios de las políticas, a partir del criterio de maximizar el número de beneficiarios de las inversiones y políticas públicas y privadas, es decir, sociales.

\subsection{La definición sobre el referente del desarrollo}

El neoliberalismo promueve la participación de los sectores populares en las políticas de reproducción de la fuerza de trabajo. En cambio, para las políticas productivas, comerciales, financieras, tributarias, sobre el manejo de los recursos estratégicos del suelo y el subsuelo no existen ofertas de participación. Éstas son la potestad del mercado y de manera creciente de actores privados trasnacionalizados.

El neoliberalismo niega la participación en las decisiones sobre la producción y distribución de la riqueza en la sociedad. En cambio, desde el campo popular la máxima aspiración es acceder a la propiedad, definir quién tributa y quién se beneficia del gasto y las políticas, controlar los circuitos comerciales para menguar el peso de los intermediarios y especuladores, construir un sistema de crédito que no despoje a los ahorradores y apoye a los trabajadores, acceder a la tecnología y el conocimiento científico, en una frase: superar la frontera de las políticas reproductoras del trabajo hacia el control y orientación del desarrollo.

\subsection{La politización expandida de los conflictos sociales}

En esta perspectiva, la participación social en los asuntos de interés colectivo, supera la práctica política como mero asunto de Estado o de intermediación, a través de prácticas representativas, gremiales y corporativas de la sociedad con el Estado.

La pérdida relativa del poder del Estado acrecienta el peso de las decisiones privadas y del mercado en la determinación de la calidad de la vida, las oportunidades de empleo y de generación de riqueza, las decisiones de inversión, los patrones de producción y consumo. Por lo tanto, las luchas democráticas suponen el tránsito de la política como mediación de la democracia representativa para los asuntos de Estado, a la discusión política de las decisiones del mercado. 
También, las prácticas participativas tienden a extender el campo de la política a las relaciones sociales y de poder en la familia, el trabajo, el ambiente, el espacio público, las relaciones internacionales, la cultura, las relaciones entre los sexos, los flujos de información, y la circulación de conocimientos e innovaciones.

Mientras el capitalismo contemporáneo y las estrategias neoliberales pugnan por una extensión de las relaciones mercantiles a todas las actividades sociales, incluyendo la cultura, el arte y la subjetividad, las prácticas participativas alternativas tienden a la politización de las relaciones sociales.

Mientras el capitalismo mercantiliza incluso a la naturaleza, pone precio al ambiente, al cuidado de los bosques y los nacimientos de agua, privatiza los beneficios de la naturaleza y de la genética humana, animal y natural mediante odiosas patentes, las prácticas políticas alternativas reclaman los derechos de la naturaleza, ejercen respeto por las especies animales y levantan barreras a la explotación de la vida humana, animal y natural.

Por último, mientras la ética capitalista somete el conocimiento, la información, los descubrimientos y la cooperación humana a la lógica privada de la acumulación y al usufructo restringido de los beneficios, la ética alternativa masifica los flujos del conocimiento, quiebra las barreras de la propiedad y socializa los beneficios de la cooperación. El capitalismo recrea privilegios feudales mediante los cuales parasita la producción social de la riqueza, cobra regalías, construye la propiedad sobre el conocimiento y la vida, expropia a los más sobre la determinación de los fines estratégicos de la vida en sociedad. La ética socialista en curso, por el contrario, construye una ética postmaterialista, ecológica y de participación colectiva sobre los fines de la vida humana.

\section{Conclusión}

Hemos llegado al término de la revisión de dos importantes componentes de la reforma del Estado. Por una parte, el proceso de descentralización que crea una nueva espacialidad para la distribución de recursos, competencias y protagonismo político. Por otra, las prácticas de participación ciudadana y comunitaria en las políticas de interés colectivo.

Ambas reformas remiten a la reestructuración del Estado, de la sociedad y de la política dentro del capitalismo contemporáneo. El proceso de globalización y la crisis del Estado benefac- 
tor constituyen el telón de fondo en el que se genera la recomposición espacial del Estado y las nuevas prácticas políticas. Diferentes actores sociales, políticos y territoriales recomponen sus estrategias en las nuevas condiciones.

Hemos considerado necesario hacer explícita la estrategia neoliberal en descentralización y participación, contrastándola con las estrategias e intereses desde los nuevos movimientos sociales. Queremos así, alimentar una diferenciación sistemática con el neoliberalismo y alertar sobre una aceptación apresurada de la descentralización y las prácticas participativas como componentes unívocos de un nuevo programa emancipador. Descentralización y participación son nuevos terrenos para la contienda entre dominación y emancipación, socialización o privatización de la política y sus logros, fragmentación de las resistencias y las alternativas o agremiación y fortalecimiento de los tejidos sociales y del campo popular.

\section{Bibliografía}

Bauman, Z. (1999), La globalización. Consecuencias humanas, Fondo de Cultura Económica, Sao Paulo, Brasil.

Beck, U. (1998), ¿Qué es la globalización? Falacias del globalismo, respuestas a la globalización, España, Paidós, Barcelona.

Bird, Richard (1981), Finanzas intergubernamentales en Colombia, Informe final, Departamento Nacional de Planeación, Bogotá, Colombia.

Calderón, M. (1987), Un nuevo municipio, un nuevo país, Colombia, Banco Central Hipotecario, Bogotá.

De Mattos C. (1989), "Reestructuración social, grupos económicos y desterritorialización del capital”, en Seminario internacional sobre revolución tecnológica y reestructuración productiva: impactos y desafíos territoriales, Santiago de Chile, Chile.

Fals, O. (2000), Acción y espacio. Autonomías en la nueva República, Colombia, Tercer mundo editores / Universidad Nacional de Colombia, Bogotá. 
Forester, V. (1996), L’Horreur économique, Fayard, París, Francia.

Guéhenno, J. M. (1995), El fin de la democracia. La crisis politica y las nuevas reglas de juego, Paidós, Barcelona, España.

González, Jorge Iván (1996), “La globalización, la moneda y el sistema financiero", Darío I. Restrepo et al., Las politicas sociales de la nueva era. Globalización y Estado Nación, Escuela Superior de Administración Pública - ESAP, Bogotá, Colombia.

Ochoa, D. y Restrepo, D. (1997), Balance politico de la descentralización. Descentralización, desarrollo institucional y democratización, Escuela Superior de Administración Pública-ESAP/ Ministerio del Interior, Bogotá, Colombia.

Prado, S. y Cavalcanti, C. (2000), A guerra fiscal no Brasil, Sao Paulo, Brasil, Fundaçao do Desenvolvimento Administrativo-FUNDAP.

Restrepo, D. (2000a), Colombia entre la guerra y la paz: descentralización o desintegración del Estado. Las claves territoriales de la guerra y la paz. Mandato ciudadano por la paz, la vida y la libertad, Bogotá, Colombia.

— (2000b), "El mito de Sísifo o veinte años de pujanza descentralizadora en Colombia", Revista Reforma y democracia, núm. 17, Centro Latinoamericano de Administración para el Desarrollo-CLAD, Caracas, Venezuela.

- (1997), Dilemas de la planeación participativa. Relaciones entre el Estado, las ONG y las comunidades. El desafío de construir politicas públicas desde lo local, Alcaldía de San José de Cúcuta, Fundación para la participación comunitaria-PARComún y Red de Solidaridad Social, Bogotá, Colombia.

- y Édgar Novoa (1996), Las políticas sociales de la nueva era. Globalización y Estado Nación, Escuela Superior de Administración Pública - ESAP, Bogotá, Colombia. 
- (1994), Los desfases de la democracia, Democracia formal y real, Instituto para el desarrollo de la democracia Luis Carlos Galán, Bogotá, Colombia.

— (1994b), “Cartografía de la descentralización. Emergencia, actualidad e indefiniciones", en Revista Interamericana de Planificación, órgano de la Sociedad Interamericana de Planificación - SIAP. núm. 105, San Antonio, Texas, Estados Unidos.

- (1992), Neoliberalismo y reestructuración capitalista. Espacialidad, descentralización y apertura. Rompiendo la corriente. Un debate al neoliberalismo, Centro de estudios e investigaciones sociales, Bogotá, Colombia.

- (1991), "Transformaciones recientes en América Latina: la descentralización, mito y potencia. El caso colombiano", en Transformaciones recientes y tendencias del Estado en América latina, Fundación Friedrich Ebert de Costa Rica, San José, Costa Rica.

Rosas Vega, Gabriel (1997), El saneamiento fiscal, un compromiso de la sociedad, Informe final de la Comisión de Racionalización del Gasto y las Finanzas Públicas, Ministerio de Hacienda y Crédito Público, Bogotá, Colombia.

Schumacher, E. (1978), Lo pequeño es hermoso, Hermann Blume ediciones, Madrid, España.

Velázquez Cock, Álvaro (1986), Comisión del gasto público, Informe final, Ministerio de Hacienda y Crédito Público, Bogotá, Colombia.

Wiesner Durán, Eduardo (1992), Colombia: descentralización y federalismo fiscal, Informe final de la Misión para la Descentralización, Departamento Nacional de Planeación, Bogotá, Colombia. 